\title{
Goal-Oriented Anxiety-Free Learning: A Teaching-Learning Theory
}

\author{
Monalie C. Saylo and Micah M. Saylo \\ University of Antique/DepEd Sibalom North District \\ Sibalom Antique, Philippines \\ net_saylo@yahoo.com
}

\begin{abstract}
Goal-Oriented Anxiety-Free Learning is a theory developed to describe variability in dispositional or situational goal preferences that the learner implicitly sets for him/herself in achievement situations. It will assist in providing a motivational framework for how the learners perceive, interpret, and judge reaction to key events in their lives. Furthermore, the theory proposes that the learner need to be conditioned for success/failure activities set for the goal to be attained in an anxiety-free environment. Hence, once the learner had been conditioned, he/she would be able to work towards attainment of the goal without any fear or worry at all. Thus, there will assurance that the learner will be able to have high learning performance.
\end{abstract}

Keywords: goal-oriented anxiety-free learning, goal-setting, learning performance

\section{Introduction}

Learning is natural; it beckons, captivates and enchants. But education is planned; it enlightens, develops and empowers.

The responsibility and the ability to learn rest within the learner himself or herself. No one can learn for someone else.

Life is filled with tasks that call for self-management, and goal- setting is very important. Learners need to be taught how to educate themselves, manage their own lives, and set their own goals for them to perform their tasks well in the future.

Learners need to set specific goals - those which are high standards. Higher standards tend to lead to higher performance. But learner-set goals have a tendency to become lower, hence, teacher's role in helping learners maintain high standards is aptly important. This can be done by monitoring the goals set and reinforcing high standards.

Goal-Oriented Anxiety-Free Learning is a theory anchored both on hehavioral and cognitive theories. The concept was developed to describe variability in dispositional or situational goal preferences that the learner implicitly sets for him/herself in achievement situations. It will assist in providing a motivational framework for how the learners perceive, interpret, and judge reaction to key events in their lives. Furthermore, the theory proposes that the learner need to be conditioned for success/failure activities set for the goal to be attained in an anxiety-free environment. Hence, once the learner had been conditioned, he/she would be able to work towards attainment of the goal without any fear or worry at all. Thus, there will assurance that the learner will be able to have high learning performance.

\section{Related Studies on Goal-Orientation}

Goal orientation refers to whether individuals primarily strive to enhance their knowledge, skills, and competence, referred to as a learning orientation, or generally 
attempt to demonstrate their abilities and expertise, referred to as a performance orientation.

According to Dweck, goal orientation (1) can be described as: 1) a learning goal orientation in which individuals approach learning to gain and assume mastery of knowledge, skills, and behaviors; or 2) a performance goal orientation in which individuals are driven to perform at a desired degree in order to achieve positive judgments or avoid unfavorable judgments (2).

All forms of learning depend upon means-end readiness that is goal-oriented behavior mediated by expectations, perceptions, representations, and other internal or environmental variables. Tolman believed that learning is always purposive and goaldirected. It often involves the use of environmental factors to achieve a goal - meansends-analysis. And organisms will select the shortest or easiest path to achieve a goal (7).

According to Tolman's theory of sign learning, an organism learns by pursuing signs to a goal, that is learning is acquired through meaningful behavior. Tolman emphasized the organized aspect of learning: "The stimuli which are allowed in are not connected by just simple one-to-one switches to the outgoing responses. Rather the incoming impulses are usually worked over and elaborated in the central control room into a tentative cognitivelike map of the environment. And it is this tentative map, indicating routes and paths and environmental relationships which finally determines what responses, if any, the animal will finally make" (8).

Studies revealed that goal-orientation among children vary based on their developmental growth, learning abilities and styles. Children differ on how they approach, interpret, and respond to situations. Students are motivationally oriented either towards learning goals or performance goals. Those with learning goals see the purpose of schooling as gaining competence in the skills being taught whereas those with performance goals primarily seek to gain positive judgements of their competence and avoid negative judgements.

Students with learning goals and those with performance goals do not differ in overall intelligence, but their classroom performance can differ markedly. When they run into obstacles, performance-oriented students tend to become discouraged and their performance is seriously hampered. In contrast, when learning-oriented students encounter obstacles, they tend to keep trying and their motivation and performance may actually increase (1). Learning-oriented students are more likely to use metacognitive or self-regulated learning strategies (3). Performance-oriented students who perceive their abilities to be low are likely to fall into a pattern of helplessness since they believe that they have little chance of earning good grades. Learning-oriented students who perceive their ability to be low do not feel this way since they are concerned with how much they themselves can learn without regard for the performance of others (5). But evidence also showed that over their years in school, students tend to shift from learning or mastery goals to performance goals (6).

Studies also revealed that learners exert more effort and thus achieve higher levels of performance on a task when goals are difficult and specific. However, this is only the case when learners are committed to the goal, believe they can accomplish the goal, and have the requisite skills.

\section{Nature of Goal-Oriented Anxiety-Free Learning}

\section{a. Wellbeing and Adjustment}

Goal orientation affects the capacity of individuals to withstand obstacles and adjust to change. Learning orientation fosters resilience to rises in workload. That is, when individuals experience a learning rather than performance orientation, this rise in 
workload, which perhaps is perceived as a challenge or opportunity to develop qualities, does not appreciably compromise work satisfaction.

Individuals with a learning orientation equate success with effort and persistence. They perceive challenging settings as opportunities to acquire knowledge and expertise maintaining their effort throughout the frustrating times. When individuals adopt a learning orientation, they perceive their tasks as a challenge and not as a threat. And when individuals perceive tasks as a challenge, instead of a threat, they do not feel as concerned by the possibility of failure (9). Their stress diminishes, and their performance often improves.

Individuals with a performance orientation, in contrast, tend to flourish primarily when they undertake tasks they have practiced or rehearsed extensively. When individuals feel they might be evaluated by an audience, this orientation can amplify anxiety Furthermore, when individuals experience a performance avoidance orientation, they strive to circumvent failures or errors. They might, as a consequence, shun the pursuit of the task preoccupied with the prospect of failure (10).

\section{b. Interpersonal Behavior}

Individuals who show learning orientation are more inclined to feel that cooperation with peers is a vital determinant of success. Cooperation is less relevant to individuals with performance orientation partly because they do not seek help as frequently, and they do not appreciate the reciprocation that often coincides with altruistic behavior. As a consequence, a performance orientation tends to curb altruism.

Individuals who pursue performance goals are more inclined to demonstrate their superiority rather than to integrate contradictory perspectives during conflicts. In contrast, when individuals attempt to master new skills instead, corresponding to a learning orientation, they strive to integrate these conflicting opinions to form a unified understanding of the issues' conflicts. Individuals with a performance orientation are likely to experience conflict and difficulty rather than trust and collaboration.

\section{c. Goal-setting and Motivation}

Individuals with a learning orientation set more challenging, suitable and effective goals. They tend to set goals that are intended to boost self improvement. While individuals with a performance orientation set goals that are intended to facilitate supremacy.

\section{d. Rapport}

Individuals with a learning orientation strive to understand rather than impress the other person. They attempt to decipher the needs, intentions and attributes of the other person. Performance oriented individuals in contrast strive to impress the other person. They are concerned about whether they will be evaluated favorably. As a consequence of this mindset, they monitor themselves closely inhibiting spontaneous behaviour, hence a limited supply of mental energy is depleted resulting to increase anxiety. Thus, sensitivity to the other person diminishes.

\section{e. Attention and Concentration}

Individuals who pursue learning orientation are more inclined to direct all their attention to the activity they are undertaking. They are able to consider the issues deeply and comprehensively. In contrast, individuals with a performance orientation are more likely to allocate some of their attention to concerns over their performance. They process issues more superficially as a consequence. 
When individuals adopt a learning orientation, their working memory seems to improve. They can retain, transform, integrate, and consider many facets or issues simultaneously. Failures and challenges are conceptualized as opportunities to improve. Performance oriented individuals tend to have a decline in working memory. They become preoccupied with doubts and concerns during challenging settings when the tasks are complex that consume working memory. Hence, they are likely to evoke anxiety and agitation.

\section{f. Learning}

Individuals with learning orientation are more likely to improve mastery performance only when the activities are difficult or elicit stress. Mastery goals facilitate learning when tasks are confusing or when failures are prevalent. Performance goals (1) impede learning partly because individuals become more inclined to learn by rote.

\section{g. Creativity and Performance}

Individuals who are performance oriented are less inclined to work creatively. They strive to fulfil the standards and expectations impose curbing their tendency to uncover original and novel solutions.

\section{Factors that Amplify or Inhibit the Effects of Goal Orientation}

\section{a. Cognitive ability and intelligence}

Learning goals tend to be more effective than performance goals when the task is challenging or unfamiliar, thus novel approaches, skills, and techniques must be developed or refined. When cognitive ability is low, learning goals might enhance the capacity of individuals to uncover suitable strategies. Performance goals (1) on the other hand, can disrupt the acquisition of skills and knowledge but if cognitive ability is high, uncovering of strategies is rapid. As a consequence, the detrimental effects of performance goals might not be as apparent. The specificity of these goals might enhance motivation without impeding progress.

\section{b. Uncertainty}

Individuals that adopt a learning orientation perceive moments in which someone disagrees with their interpretation as opportunities to advance their knowledge. They remain engaged in their task and attempt to explore the source of this uncertainty or disagreement. In contrast, if individuals adopt a performance orientation, they perceive these moments of disagreement as obstacles to their goals. Their confidence declines, their engagement in the task diminishes and their learning deteriorates.

\section{c. Workplace environment}

Individuals with a learning orientation are more likely than individuals with a performance orientation to flourish in dynamic, innovative environments. These environments offer the variety and challenges that are needed to facilitate growth, fulfilling the needs, and thus enhancing the motivation, of individuals with a learning orientation. These environments, however, obstruct the attempts of individuals to exceed some target or standard, compromising the needs, motivation, and ultimately performance of people with a performance orientation. 


\section{d. Resource availability and time}

If resources are scarce, individuals cannot pursue both learning and performance goals at the same time. The impact of a learning or performance orientation particularly in response to some change or crisis will depend on resource availability.

The practical implication is that, when resources are available, a learning orientation should be encouraged. When resources are scarce, after a crisis, performance expectations should be reduced appreciably but enforced rigorously.

\section{Problems Confronting Goal Orientation}

One problem that distorts goal orientation is learned helplessness- an extreme form of avoiding failure which is the perception that no matter what one does, one is doomed to failure or ineffectuality. Learned helplessness can arise from a child's upbringing or from inconsistent, unpredictable use of rewards and punishments by teachers leading students to believe that there is little they can do to be successful (4).

Another problem is anxiety which is a constant companion of education. Every student feels some anxiety at some time while in school. But for certain students, anxiety seriously inhibits learning or performance particularly on tests. Anxiety is a feeling of nervousness, apprehension, fear, or worry. It affects our whole being- affecting how we feel, and how we behave. Hence, this is considered as detrimental to the learning performance of children.

The main source of anxiety in school is the fear of failure and with it, loss of selfesteem. Low achievers are particularly likely to feel anxious in school but they are not the only ones. Very able high-achieving students are also very anxious and maybe even terrified to be less than perfect at any school task.

Anxiety can block school performance in several ways. Anxious students may have difficulty learning in the first place; they may have difficulty using or transferring knowledge they do have; and they may have difficulty demonstrating their knowledge on tests. Anxious students are likely to be overly self-conscious in performance settings, a feeling that distracts attention from the task at hand.

\section{Implication}

The two most common dimensions of goal orientation are mastery-oriented or learning-oriented and performance-oriented or achievement-oriented. Performance-goal orientation is the motivation that shows one's competence or ability on a certain task or subject. Learning-goal orientation is a motivation to acquire new knowledge or attain a deeper understanding of a certain task or subject.

The benefits of having a high mastery goal orientation are associated with a high level of interest, and having a high-performance goal orientation is associated with a high level of performance on the task.

The most important implication of learning and performance goals is that teachers would be able to convince students that learning rather than grades is the purpose of academic work. Studies revealed that the types of tasks that are used in classrooms have a strong influence on students' adoption of learning goals (12). Use of tasks that are challenging, meaningful, and related to real life are more likely to lead to learning goals than are other tasks.

It was also noted in studies done that individuals may be motivated to achieve in either of two ways: to seek success or to avoid failure (11). It was found out that people are more motivated to avoid failure than to seek success while others were more motivated to seek success than to avoid failure. Success seekers' motivation is increased after a failure as they intensify their efforts to succeed. Failure avoiders decrease their efforts after a failure (9). They tend to prefer either easy tasks or such difficult tasks that no one would 
blame them if they failed. Understanding these conditions among teachers is very important for them to be able to attend to these situations in planning lessons and tasks for their students. Teachers need to arrange learning environment in such a way that students would be able to feel relax and calm even if given success/failure tasks, they can perform well.

\section{Application}

Presented with the different problems confronting goal orientation among learners, goal-oriented anxiety-free learning proposes that educators should evaluate the learner's learning status prior to immersing them into any learning or performance tasks. In this manner, educators would be able to plan and design curriculum apt for these learners, and set up or arrange learning environment which will help promote positive outlook for learners, hence feeling of anxiety towards school could be reduced. This will also help improve the self-esteem of the learners promoting high learning and performance standards on them.

Furthermore, the theory also proposes that great responsibility lies ahead for the teachers so that this learning theory will be applicable and beneficial to both the learners and the teachers themselves. Teachers need to consider every aspect of learning, the learning process itself, the learning environment, the student's developmental growth as well as his/her learning abilities and styles.

Teachers may apply many strategies to reduce the negative impact of anxiety on learning and performance. Suggested strategies are: creating a learning environment that is accepting, comfortable and non-competitive, hence classroom management is very important; giving students the opportunity to correct errors or improve their work before handing it will help anxious children as well as providing clear, unambiguous instructions; using special programs such as attribution training to help students out of learned helplessness; communicating positive expectations that students can learn and can take steps to reduce anxiety; enhancing intrinsic as well as extrinsic motivation; and using cooperative learning methods emphasizing cooperative goal structures over competitive goal structures and reward effort and improvement.

\section{Conclusion}

A number of factors influence a learner's success. These include the social and cultural milieu; individual learner differences; motivation; age; attitude; and the setting or context in which learning takes place.

Learning occurs within each individual as a continual process throughout life. People learn at different speeds, so it is natural for them to be anxious or nervous when faced with a learning situation. It is evident that students generally learn better when they are relaxed thoroughly and consistently than when they are anxious and nervous. And for successful learning, teaching-learning environment should be friendly, stress-free, easy, associative and enjoyable.

A comfortable, attractive learning setting; relaxed state-physically and mentally; and a positive and encouraging learning atmosphere enhances learning. Thus, success in learning heightens self-concepts and promotes personal adjustment and self-confidence.

\section{References}

[1] C. S. Dweck, "Motivational processes affecting learning", American Psychologist, vol. 41, (1986), pp, 1040-1048.

[2] C. S. Dweck, "Self-theories: Their role in motivation, personality, and development", Philadelphia, PA: Psychology Press, (1999). 
[3] J. L. Meech, S. Miller and J. Ferron, "Longitudinal changes in elementary school students: Achievement goal orientations", Paper presented at the annual meeting of the American Educational Research Association, San Francisco, (1995) April.

[4] J. L. Meece and D. H. Daniels, "Child and Adolescent Development for Educators", $3{ }^{\text {rd }}$ ed. McGrawHill Higher Education, (2008).

[5] J. G. Nicholls, "Achievement motivation: Conceptions of ability, subjective experience, task choice, and performance", Psychological Review, vol. 91, (1984), pp. 328-346.

[6] P. R. Pintrich, R. W. Marx and R. A. Boyle, "Beyond cold conceptual change: The role of motivational beliefs and classroom contextual factors in the process of conceptual change", Review of Educational Research, vol. 63, no. 2, (1993), pp. 167-199.

[7] E. C. Tolman, "Purposive Behavior in Animals and Men", New York: Appleton-Century-Crofts, (1932).

[8] E. C. Tolman, "Cognitive maps in rats and men", Psychological Review, vol. 55, (1948), pp. 189-208.

[9] B. Weiner, "An Attributional Theory of Motivation and Emotion", Springer Verlag, New York, (1986).

[10] B. Weiner, "Human Motivation: Metaphors, Theories, and Research", Sage, Newbury Park, CA, (1992).

[11] R. E. Slavin, "Educational Psychology: Theory and Practice", $5^{\text {th }}$ ed. A Viacom Company, (1997).

[12] A. E. Woolfolk, "Educational Psychology", $7^{\text {th }}$ ed. A Viacom Company, (1998). 
International Journal of Education and Learning Vol.4, No.1 (2015) 